\title{
Lipid Production of Microalga Ankistrodesmus falcatus Increased by Nutrient and Light Starvation in a Two-Stage Cultivation Process
}

\author{
Pablo David Álvarez-Díaz • Jesús Ruiz • Zouhayr Arbib • \\ Jesús Barragán • Carmen Garrido-Pérez • \\ José Antonio Perales
}

Received: 12 March 2014 / Accepted: 23 July 2014 /

Published online: 14 August 2014

(C) Springer Science+Business Media New York 2014

\begin{abstract}
The aim of this work was to study the stimulation of lipid production on the microalga Ankistrodesmus falcatus by varying cultivation conditions during the stationary phase. The effect of three factors (presence and absence of nitrogen, phosphorus, and light) has been tested once the cultures reached the stationary phase with the aim to increase the value of the biomass for further applications. Lipid content, elemental composition, Nile red fluorescence evolution, and calorific value of microalgal biomass were studied as well as biomass growth. Biomass presented a lipid content of $36.54 \%$ at the end of the first stage, while at the end of the second stage, the experiments with the absence of phosphorus increased their lipid content until 45.94 and $44.55 \%$, the first with nitrogen and light presence and the second with absence of all factors. The combination of phosphorus absence and nitrogen and light presence achieved the highest lipid productivity $(20.27 \mathrm{mg} / \mathrm{L} /$ day $)$. The two-stage strategy to culture microalgae is a feasible option to increase the economic or energetic value of biomass.
\end{abstract}

Keywords Microalgae - Ankistrodesmus falcatus · Two-stage cultivation · Nutrient starvation · Lipid· Energy

\section{Introduction}

Microalgae are photosynthetic microorganisms that offer an alternative renewable source of energy for the increasing demand of oil and gas resources; they accumulate lipids and carbohydrates which make them good feedstocks for the production of biofuels [1]. Lipids from microalgae can be extracted and chemically processed into biodiesel [2]; also, the

P. D. Álvarez-Díaz $(\bowtie) \cdot J$. Ruiz $\cdot$ Z. Arbib · J. Barragán • C. Garrido-Pérez • J. A. Perales Environmental Technologies Department, Andalusian Center of Science and Marine Technology (CACYTMAR), Universidad de Cádiz, Campus of Puerto Real, 11510 Puerto Real, Cádiz, Spain e-mail: pablo.alvarez@uca.es

J. Barragán

Chiclana Natural S.A.M., Plaza de España S/N, 11130 Chiclana, Cádiz, Spain 
conversion of algal biomass after lipid extraction into methane, through anaerobic digestion (AD), can enhance the energy recovery of the biofuel production process [3].

Some species achieve up to $60 \%$ lipids on dry weight [4] ranging from 10 to $60 \%$ depending on the strain and the culturing conditions [5]. Nutrient deficiency is well known to enhance the lipid content of algae; moreover, growth under different light intensities exhibits remarkable changes in their gross chemical composition [6]. Chen and Johns [7] demonstrated that fatty acid composition and lipid content of heterotrophically grown microalgae can be favorably manipulated by varying culture conditions. Many algal species were reported to accumulate lipids under nitrogen starvation [8-10] and phosphorus limitation [11, 12]. Similarly, light limitation can lead to a substantial increase in oil content, but also limits growth that could result in overall lower oil productivity.

The energetic use of microalgae biomass is not restricted to the lipid fraction conversion to biodiesel or the AD. Green algae have shown to accumulate high levels of polysaccharides and starch that can be used in the production of bioethanol. Some authors have shown that lipid-extracted microalgae can be used as fermentation substrate for bioethanol production [13]. Alternatively, microalgae with low lipid content or residues from lipid extraction can be thermochemically processed, e.g., pyrolysis on dry biomass or hydrothermal treatment (HTT) on wet matter can produce liquid fuels by exploiting all biomass constituents as lipids, carbohydrates, proteins, and polysaccharides [14]. Pyrolysis produces energy fuels with high fuel-to-feed ratio by heating the biomass at atmospheric pressure in the absence of oxygen; fast pyrolysis is a high-temperature process in which biomass is rapidly heated [15]; and also, catalytic pyrolysis processes are currently being studied [16].

Several authors proposed a two-stage strategy for the cultivation of microalgae for the subsequent production of lipids or other valuable compounds, first a nutrient-sufficient biomass production stage followed by a nutrient starvation or other physiological stress stage $[17,11]$. Huntley and Redalje [18] presented the two-stage strategy in a hybrid closed photobioreactor/open pond microalgal cultivation system. Prathima Devi et al. [19] reported satisfactory experimental results for that dual mode of operation for the heterotrophic cultivation of microalgae for lipid accumulation. Kleinegris et al. [20] proposed the two-stage systems of microalgae production and in situ extraction of valuable products to lower production costs and to avoid cell harvesting steps. Therefore, establishing the physical or chemical factors and their interactions that can increase the energetic or economic value of microalgae in a second cultivation stage becomes a matter of interest.

In this regard, the objective of this study was to alter the biochemical composition of the green alga Ankistrodesmus falcatus under different combinations of major nutrients starvation, i.e., nitrogen, phosphorus, and light at the stationary growth phase. A. falcatus is a strong candidate for biodiesel production due to its high lipid productivity [5] and high level of quality fatty acids which would produce a biodiesel with good properties as a low cetane number, high iodine value, and low oxidation stability [21]. This study will allow exploring different opportunities for the energetic revalorization of biomass.

\section{Methods}

Microorganism

A. falcatus (SAG-202-2) was obtained from Sammlung von Algenkulturen, Pflanzenphysiologisches Institut (Universität Göttingen, Germany). Stock cultures were 
maintained routinely in liquid COMBO medium [22] by regular subculturing at 2-week intervals. Cultures were maintained axenic at $20 \pm 1{ }^{\circ} \mathrm{C}$ temperature with $143 \mathrm{PAR} \mu \mathrm{mol} / \mathrm{m}^{2}$ / s light intensity under 14/10 light/dark cycle.

\section{Culture Medium}

The medium selected was the synthetic COMBO medium [22]. COMBO medium was composed of (per liter): $85.01 \mathrm{mg} \mathrm{NaNO}_{3}, 8.71 \mathrm{mg} \mathrm{K}_{2} \mathrm{HPO}_{4}, 36.76 \mathrm{mg} \mathrm{CaCl}{ }_{2} \mathrm{H}_{2} \mathrm{O}$, $36.97 \mathrm{mg} \mathrm{MgSO}_{4} \cdot 7 \mathrm{H}_{2} \mathrm{O}, 12.6 \mathrm{mg} \mathrm{NaHCO}_{3}, 24 \mathrm{mg} \mathrm{H}_{3} \mathrm{BO}_{3}, 7.45 \mathrm{mg} \mathrm{KCl}, 4.36 \mathrm{mg}$ $\mathrm{Na}_{2}$ EDTA $\cdot 2 \mathrm{H}_{2} \mathrm{O}, 1 \mathrm{mg} \mathrm{FeCl}{ }_{3} \cdot 6 \mathrm{H}_{2} \mathrm{O}, 1 \mathrm{mg} \mathrm{CuSO}{ }_{4} \cdot 5 \mathrm{H}_{2} \mathrm{O}, 22 \mathrm{mg} \mathrm{ZnSO}_{4} \cdot 7 \mathrm{H}_{2} \mathrm{O}, 12 \mathrm{mg}$ $\mathrm{CoCl}_{2} \cdot 6 \mathrm{H}_{2} \mathrm{O}, 180 \mathrm{mg} \mathrm{MnCl}_{2} \cdot 4 \mathrm{H}_{2} \mathrm{O}, 22 \mathrm{mg} \mathrm{Na} \mathrm{MoO}_{4} \cdot 2 \mathrm{H}_{2} \mathrm{O}, 1.6 \mathrm{mg} \mathrm{H}_{2} \mathrm{SeO}_{3}, 1.8 \mathrm{mg}$ $\mathrm{NaVO}_{4}, 100 \mu \mathrm{g}$ thiamin $\cdot \mathrm{HCl}\left(\mathrm{B}_{1}\right), 0.5 \mu \mathrm{g}$ Biotine (Vitamin $\mathrm{H}$ ), and $0.55 \mu \mathrm{g}$ cyanocobalamin $\left(\mathrm{B}_{12}\right)$. For this study, the term "rest of nutrients" will be used to denominate all components of the medium different to nitrogen and phosphorus.

\section{Experimental Design}

To study the effects of nitrogen (N), phosphorus (P), and light (L) presence or absence on already-grown biomass, the experimental design included all possible combinations among these factors (Table 1). Thus, 11 different flasks containing A. falcatus in COMBO medium were carried in batch in a first stage of $180 \mathrm{~h}$ until stationary growth phase was reached. Then, in a second stage, all COMBO nutrients were resupplied to eight flasks but with nitrogen and phosphorus restrictions as well as different light conditions according to Table 1. Also, two control reactors without any nutrient resupplying were maintained, one of them in the presence of light and the other one in dark.

One photobioreactor was stopped at the stationary growth phase before the beginning of the second stage and its biomass was sampled as control of lipid, carbon, hydrogen, and nitrogen content.

Table 1 Experimental design

\begin{tabular}{lllll}
\hline Experiment & Nitrogen resupply & Phosphorus resupply & Light & The rest of nutrients resupply \\
\hline $0{\text { ffirst stage control })^{\mathrm{a}}}^{\mathrm{a}}$ & - & - & - & - \\
$1(-\mathrm{N}-\mathrm{P}-\mathrm{L})$ & - & - & - & + \\
$2(+\mathrm{N}-\mathrm{P}-\mathrm{L})$ & + & - & - & + \\
$3(-\mathrm{N}+\mathrm{P}-\mathrm{L})$ & - & + & - & + \\
$4(+\mathrm{N}+\mathrm{P}-\mathrm{L})$ & + & + & - & + \\
$5(-\mathrm{N}-\mathrm{P}+\mathrm{L})$ & - & - & + & + \\
$6(+\mathrm{N}-\mathrm{P}+\mathrm{L})$ & + & - & + & + \\
$7(-\mathrm{N}+\mathrm{P}+\mathrm{L})$ & - & + & + & + \\
$8(+\mathrm{N}+\mathrm{P}+\mathrm{L})$ & + & + & + & + \\
$9\left(\right.$ dark control ${ }^{\mathrm{b}}$ & - & - & - & - \\
$10(\text { light control })^{\mathrm{c}}$ & - & - & + & - \\
\hline
\end{tabular}

Minus sign and plus sign mean, respectively, the absence and presence of factors on the second stage

${ }^{\text {a }}$ Control experiment of the first stage $(180 \mathrm{~h})$

${ }^{\mathrm{b}}$ Experiment 9 continued in dark conditions without any nutrient supply

${ }^{\mathrm{c}}$ Experiment 10 continued with light and without any nutrient supply 
Experimental Setup

Experiments were conducted in batch by using 1,000-mL flasks. Illumination was provided from the top of the flasks by means of eight fluorescent lamps (four PHILIPS Master TLD $58 \mathrm{~W} / 840$ and four SYLVANIA Gro-Lux F $58 \mathrm{~W} / \mathrm{GRO}-\mathrm{T} 8$ ) with $143 \mu \mathrm{mol} / \mathrm{m}^{2} / \mathrm{s}$ PAR light intensity and 14/10 light/dark cycle. Light intensity was measured by a digital light meter (Hansatech QRT1 Quantitherm light meter). The experiments were conducted at $20 \pm 2{ }^{\circ} \mathrm{C}$ in a thermostatic chamber. Aeration was supplied at a flow rate of $1 \mathrm{v} / \mathrm{v}$ per minute with $0.5 \%$ of $\mathrm{CO}_{2}$ enrichment to ensure dissolved carbon availability for cultures. To achieve light absence, photobioreactors were covered with opaque film to unable light penetration. All experiments were finished $180 \mathrm{~h}$ after the end of the first stage.

Analytical Methods

\section{Biomass Monitoring}

Biomass growth was periodically evaluated (at least every $24 \mathrm{~h}$ ) through the correlation (Eq. 1) between optical density $\left(\mathrm{OD}_{680}\right)$ measured at $680 \mathrm{~nm}$ in a spectrophotometer (Thermo GENESYS 10-Vis) and the dry weight of algal biomass determined gravimetrically as suspended solids (SS) according to the standardized method 2540-D [23].

$$
\mathrm{SS}(\mathrm{g} / \mathrm{L})=0.419 \cdot \mathrm{OD}_{680}-0.021 \quad R^{2}=0.99
$$

\section{Elemental Analysis of the Biomass}

At the end of the experiments, biomass was harvested by centrifugation at 4,000 rpm for $10 \mathrm{~min}$, washed with deionized water twice, and dried in a lyophilizer (Labconco, FreeZone Triad Cascade Benchtop) under high vacuum $\left(2 \cdot 10^{-3}\right.$ mbar; $\left.-40{ }^{\circ} \mathrm{C}\right)$ during $72 \mathrm{~h}$. The percentage of elementary carbon $(\% \mathrm{C})$, hydrogen $(\% \mathrm{H})$, and nitrogen $(\% \mathrm{~N})$ content of dry biomass was determined in triplicate using an elementary analyzer (LECO, CHNS-932). Carbon to nitrogen ratio $(\mathrm{C} / \mathrm{N})$ is calculated with the relation between $\% \mathrm{C}$ and $\% \mathrm{~N}$.

\section{Total Lipid Determination}

Total lipid (TL) were extracted according to the modified method reported in [24]. Ninety milligrams of lyophilized biomass was mixed with $12 \mathrm{~mL}$ of 2:1 trichloromethane/methanol and $0.6 \mathrm{~g}$ of analytical grade quartz (particle size 10-30 $\mu \mathrm{m}$ ) was added [25]. Samples were sonicated for $90 \mathrm{~min}$ in an ultrasound bath $(35 \mathrm{kHz} ; 80 \mathrm{~W})$. The solvent was collected and the extraction was repeated twice. Final extracts were centrifuged at 5,000 rpm for $10 \mathrm{~min}$ and filtered by $1-\mu \mathrm{m}$ glass fiber filter to ensure separation of solids. Then, solvents of the final organic phase were removed under vacuum in a rotary evaporator at $65^{\circ} \mathrm{C}$. The remainder was dried in a desiccator and weighed as TL. All extractions were done in triplicate.

\section{Nile Red Fluorescence Estimation of Neutral Lipid Evolution}

Nile red fluorescence was measured during the experiments as an indirect measure of biomass neutral lipid content [26]. Ten milliliters of sample from the photobioreactors were frozen at $-4{ }^{\circ} \mathrm{C}$ until analysis. Dimethyl sulfoxide (DMSO) was introduced to defrosted microalgal 
samples as stain carrier to perform lipid staining through the cell wall. Five milliliters of algal cultures were mixed with $0.75 \mathrm{~mL}$ of DMSO. Then, $50 \mu \mathrm{L}$ of Nile red stock solution in acetone $(250 \mathrm{mg} / \mathrm{L})$ were added. Mixture was vigorously shook in a vortex during $1 \mathrm{~min}$ and incubated for $10 \mathrm{~min}$ at $37^{\circ} \mathrm{C}$ in darkness [27].

The excitation and emission wavelengths for the fluorescence determination were 490 and $580 \mathrm{~nm}$, respectively, as reported by Chen et al. [28]. Fluorescence intensity was measured on a Thermo Quantech Digital Filter Fluorimeter equipped with a 490-nm excitation narrow bandpass filter (center at $490 \pm 10 \mathrm{~nm}$ ) and a 550-nm emission sharp-cut filter (37\% transmission at $550 \mathrm{~nm}$ and maximum transmission up to 585 until $900 \mathrm{~nm}$ ).

A blank sample was prepared according the described procedure but with $5 \mathrm{~mL}$ of distilled water instead of microalgae samples. Autofluorescence of non-stained samples was subtracted from fluorescence intensities.

\section{Calculation Methods}

\section{Batch Kinetic Coefficients of Biomass Growth}

Batch growth biokinetics of the cultures were obtained through a non-linear regression of the optical density experimental data versus time. The growth kinetic model used was Verhulst model [29] (Eq. 2). Experimental data were fitted to the model minimizing the sum of squared residuals using the Microsoft Excel Solver tool, which uses a non-linear programming algorithm called GRG2, an implementation of the generalized reduced gradient algorithm [30].

$$
\frac{d X^{\prime}(t)}{d t}=\mu \cdot X^{\prime}(t)\left[1-\frac{X^{\prime}(t)}{X^{\prime} m}\right]
$$

Where: $X^{\prime}(t)$ is the optical density at $t$ time $\left(\mathrm{OD}_{680}\right), X^{\prime} m$ is the maximum optical density reached $\left(\mathrm{OD}_{680}\right)$ and $\mu$ is the maximum specific growth rate (per day).

Kinetic parameters of optical density obtained, $X_{0}^{\prime}$ and $X_{m}^{\prime}$, were expressed in terms of biomass concentration (gSS/L) via Eq. 1 and further referred to them in these units as $X_{0}$ and $X_{m}$.

Biomass productivity (BP) was calculated by dividing the amount of biomass $\left(X_{m}\right)$ produced by the duration of the first and second stage $(360 \mathrm{~h})$.

\section{Outlier Detection from Biomass Data}

Outliers were numerically detected to establish significant differences among the biomass data through the following expression [31]:

$$
\begin{aligned}
& \geq Q_{1}-1.5\left(Q_{3}-Q_{1}\right) \\
& \leq Q_{3}+1.5\left(Q_{3}-Q_{1}\right)
\end{aligned}
$$

where $Q_{1}$ is the first quartile and $Q_{3}$ is the third quartile.

\section{Calorific Values}

Higher heating value (HHV) was calculated based on the multivariate equation (Eq. 4) proposed by Callejón-Ferre et al. [32] to predict the HHV of greenhouse crop residues involving elemental analysis (carbon, hydrogen, and nitrogen). Coefficient of determination 
$\left(R^{2}\right)$ and adjusted $R^{2}$ values obtained in [32] for this multivariate model were 0.992 and 0.990 , respectively, at a $95 \%$ confidence level.

$$
\mathrm{HHV}=-3.393+0.507[\% \mathrm{C}]-0.341[\% \mathrm{H}]+0.067[\% \mathrm{~N}]
$$

\section{Lipid Production}

Lipid productivity (LP) is calculated as the product of the lipid content (TL) and the BP.

\section{Results and Discussion}

Biomass Growth

Biomass growth of the experiments is presented in Fig. 1, and kinetic parameters of the Verhulst model adjustment (Eq. 2) are presented in Table 2. On the first stage $(0-180 \mathrm{~h}$, experiment 0 ), data from all reactors were considered together for kinetic modeling. On the second stage, biomass growth only occurred in experiments $6(+\mathrm{N}-\mathrm{P}+\mathrm{L})$ and $8(+\mathrm{N}+\mathrm{P}+\mathrm{L})$; they were detected as outliers through the statistical analysis; and thus, it was considered that a significant biomass growth occurred. Then, these were the only experiments that were fitted to the Verlhust model to obtain their kinetic parameters.

At the end of the first stage, $X_{m}$ was $0.392 \mathrm{~g} / \mathrm{L}$. Then, experiments $6(+\mathrm{N}-\mathrm{P}+\mathrm{L})$ and $8(+\mathrm{N}+$ $\mathrm{P}+\mathrm{L})$ presented a second stage $X_{m}$ of 0.662 and $0.702 \mathrm{~g} / \mathrm{L}$ and increased their biomass with respect to the first stage in 69.05 and $79.34 \%$, respectively. Both experiments had common factors nitrogen and light presence. Therefore, the lack of nitrogen was the cause of the growth stop in the first experimental stage; moreover, microalgae grew in experiment $6(+\mathrm{N}-\mathrm{P}+\mathrm{L})$ but not in $7(-\mathrm{N}+\mathrm{P}+\mathrm{L})$.

\section{Lipid Productivity}

At the end of the first stage, biomass presented TL content of $36.54 \%$ (Table 2); all experiments increased their TL with respect to the first stage excluding experiments $4(+\mathrm{N}+$

Fig. 1 Biomass growth during first and second stages of the experimentation

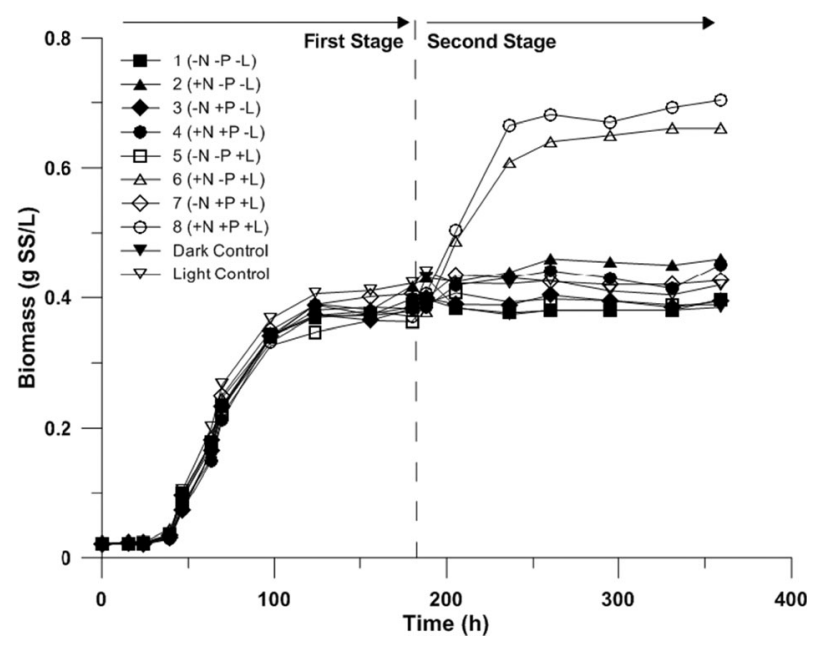




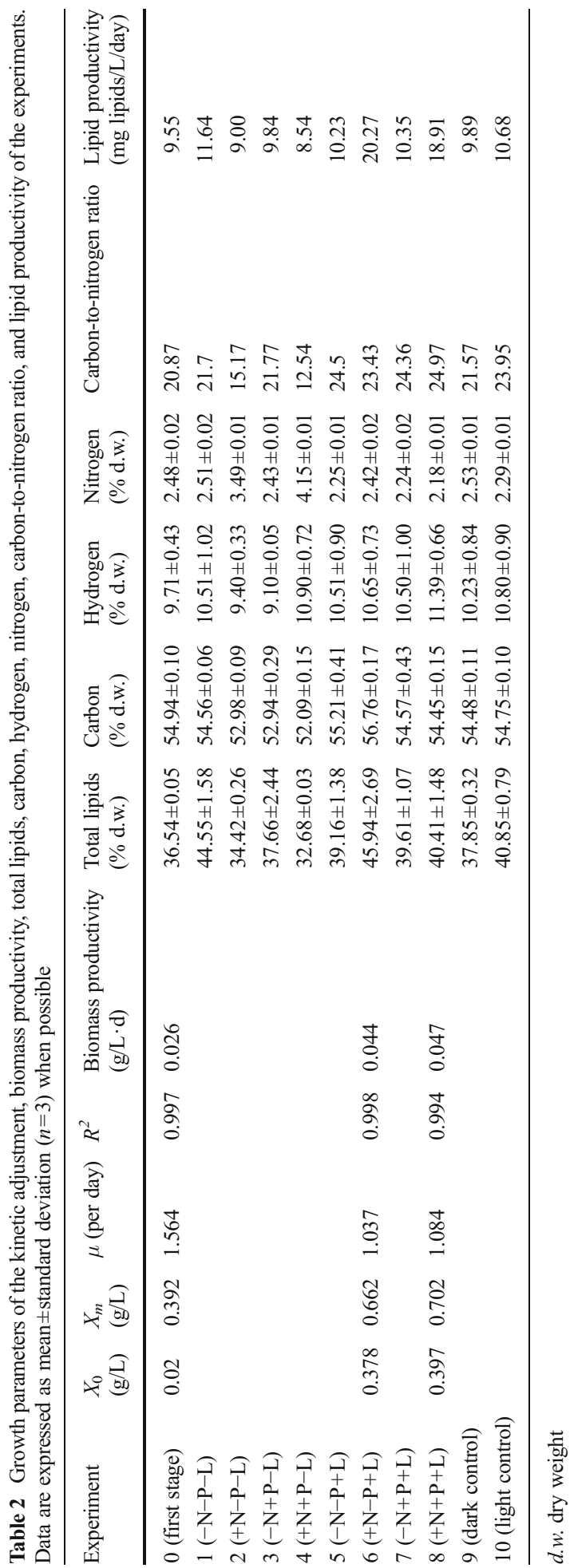


P-L) and 2 (+N-P-L) which decreased their TL until 34.42 and $32.68 \%$, respectively. Both experiments had common factors the presence of nitrogen and the absence of light.

The experiments with the highest TL were experiment 1 (-N-P-L) $44.55 \%$ and experiment $6(+\mathrm{N}-\mathrm{P}+\mathrm{L}) 45.94 \%$; in both cases, phosphorus absence occurred. That is in accordance with results obtained by Kilham et al. [33]; those authors also reported lipid enrichment under phosphorus limitation conditions.

The factor combination of experiment $6(+\mathrm{N}-\mathrm{P}+\mathrm{L})$ promoted an increase in $\mathrm{Xm}$, related to the nitrogen and light presence, and also an increase in TL related to the phosphorus absence; that factor combination boosted the LP being the highest of all experimentation $(20.27 \mathrm{mg} / \mathrm{L} /$ day) and doubling LP with respect to the first stage.

Experiment $8(+\mathrm{N}+\mathrm{P}+\mathrm{L})$ also presented an elevated $\mathrm{LP}(18.91 \mathrm{mg} / \mathrm{L} \cdot$ day $)$ almost doubling the initial LP and mostly due to the high Xm rather than to its lipid content (Table 2).

In control experiments 9 and 10, where there was not a nutrient resupply, an increase of the LP with respect to the first stage occurred. The culture aging in the presence of light produced an increase of final TL; this fact was previously reported [6]. The increase in TL was higher in the presence of light, experiment 10 (40.85\%), than in absence, experiment 9 (37.58\%). This decrease in the lipid content can be attributed to respiration processes as they are not compensated by photosynthesis.

When experiments with and without the rest of nutrients presence are compared, it can be established that the presence of these rest of nutrients in dark conditions enhances final TL. Specifically, experiment 1 ( $-\mathrm{N}-\mathrm{P}-\mathrm{L})$ presented an elevated TL of $44.55 \%$ in the absence of the three factors and with the rest of nutrient resupply. In contrast, experiment 9 (dark control) with the same experimental conditions but without the rest of nutrients resupply only increased TL until $37.85 \%$. On the other hand, experiment $5(-\mathrm{N}-\mathrm{P}+\mathrm{L})$ presented a TL of $39.16 \%$ with the rest of nutrient presence while experiment 10, having the same experimental conditions but without the rest of nutrients presence, presented a higher TL of $40.85 \%$.

\section{Nile Red Fluorescence}

Nile red fluorescence evolution of the experiments is presented in Fig. 2. Fluorescence emission was relativized to the biomass of each sample and expressed in terms of fluorescence units $(\mathrm{FU})$ per gram of biomass (FU/g).

Three different patterns on fluorescence evolution depending on the experimental conditions can be described (Fig. 2). The first pattern occurred in the first experimental stage in which a direct coupling between the relative fluorescence and the growth phase can be observed, meaning that at the beginning of the logistic growth phase, the relative fluorescence was low and once stationary phase was achieved, the relative fluorescence increased until stabilization. A similar evolution was observed on the second stage in those experiments with increase of biomass concentration, experiments $6(+\mathrm{N}-\mathrm{P}+\mathrm{L})$ and $8(+\mathrm{N}+\mathrm{P}+\mathrm{L})$. Besides, once cultures were re-enriched with nitrogen and the rest of nutrients, then the fluorescence decreased in relation with the increase in biomass. Moreover, fluorescence increased as experiments were maintained at the stationary phase. This fact is related to the culture aging, or senescence of cultures, that affects lipid content and composition increasing total lipid content [6] with time.

The second pattern (Fig. 2.) was related to experiments where cultures did not present biomass growth at the second stage. Experiments $1(-\mathrm{N}-\mathrm{P}-\mathrm{L}), 3(-\mathrm{N}+\mathrm{P}-\mathrm{L})$, and $5(-\mathrm{N}-\mathrm{P}+\mathrm{L})$ described an initial increase in the relative fluorescence followed by a stabilization and a slightly final decrease. The only common factor for them was the absence of nitrogen and the re-enrichment with the rest of nutrients. 

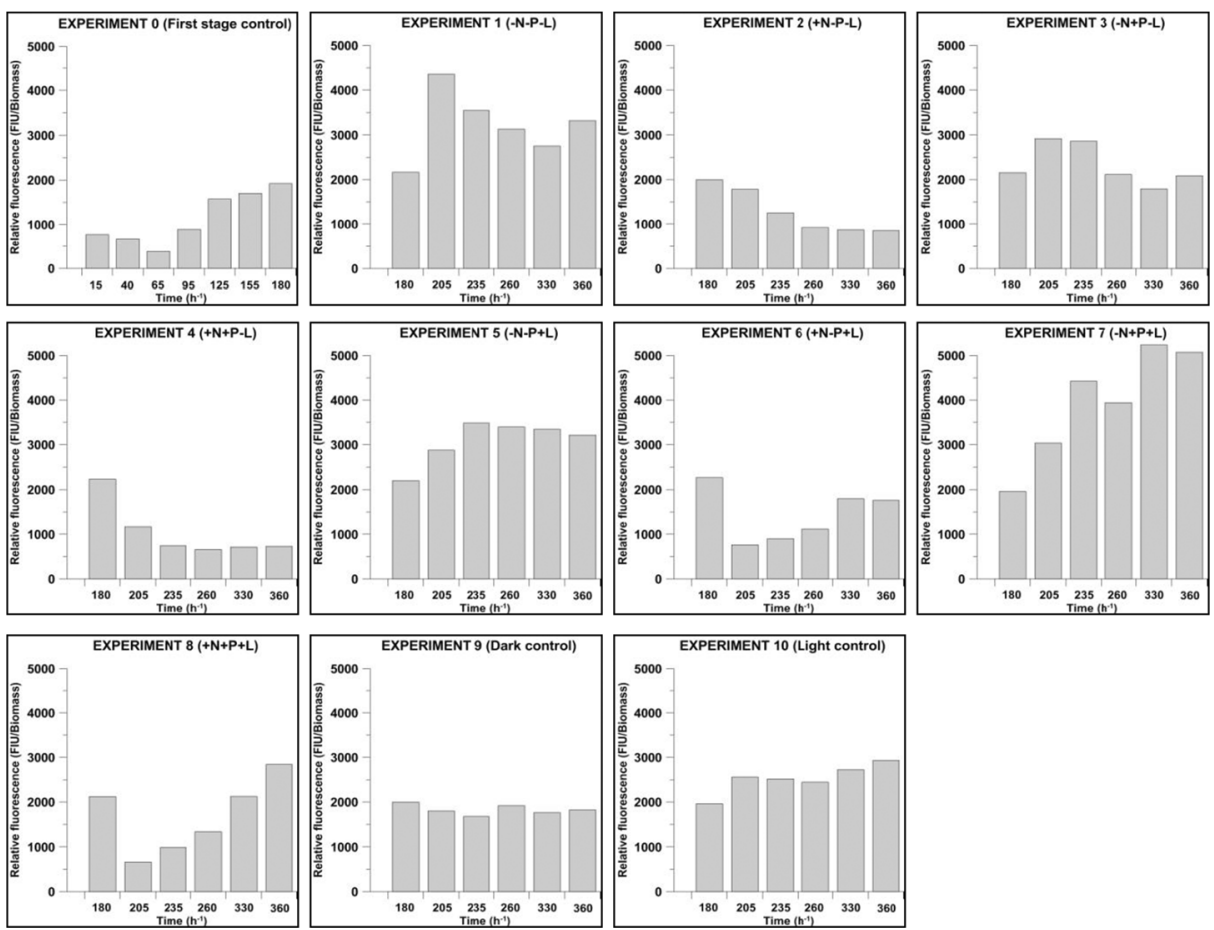

Fig. 2 Relative fluorescence evolution of the experiments. Vertical bars are fluorescence units per gram of biomass $(\mathrm{FU} / \mathrm{g})$

The third pattern, a fluorescence decrease, was also related to those experiments with the absence of biomass growth; in experiments $2(+\mathrm{N}-\mathrm{P}-\mathrm{L})$ and $4(+\mathrm{N}+\mathrm{P}-\mathrm{L})$, the fluorescence decreased. That took place only in the experiments having nitrogen presence and light absence. These both experiments also were those with lower TL results at the end of the second stage than at the end of the first stage.

For control experiments without the rest of nutrient presence, experiment 9 (dark control) and experiment 10 (light control), fluorescence presented stability in the case of light absence and a slightly increase in the case of light presence. Those small variations in fluorescence can be directly related to the slight lipid increase of those experiments reported in the previous section.

An abnormal fluorescence evolution in experiment $7(-\mathrm{N}+\mathrm{P}+\mathrm{L})$ can be observed (Fig. 2). In this case, the relative fluorescence doubled its intensity respecting to the rest of experiments. That fact was not related to an abnormal LC of the biomass (Table 2), and suggests an interaction of the dye with a hydrophobic non-lipidic compound generated by the algae under these conditions. Nile red dye is able to present fluorescence when attached to hydrophobic structures of non-lipidic compounds such as proteins [34] and sugar-based polymers [35] such as exopolymeric compounds (EPs).

The production of EPs by phytoplankton is widely reported. EPs range in structure from being loose slimes to tight capsules surrounding the cells [36]. EP release is a typical event in many stationary phase cultures in which extracellular material accumulates because cell productivity continues whereas growth stops [37]. Previous works described the formation of microgels from EPs extracted from microalgae cultures $[38,39]$. In those experiments, the 
authors demonstrated that assembly is progressive with time as microgel hydrophobicity increases, those authors also used the Nile red dye indicator to detect hydrophobic EPs.

A similar release of EPs process could be related to experiment $7(-\mathrm{N}+\mathrm{P}+\mathrm{L})$, Vieira and Myklestad [40] reported the production of EPs in Ankistrodesmus densus related to the presence of light; also, Paulsen et al. [41] studied EPs from this alga, and Chen et al. [39] reported the high hidrophobicity and short time to form a microgel of EPs released by Ankistrodesmus angustus suggesting a high content of proteins on them.

Then, this Nile red fluorescence results indicated that the hydrophobicity of EPs released by A. falcatus on experiment $7(-\mathrm{N}+\mathrm{P}+\mathrm{L})$ could promote the abnormal fluorescence registered that was not related to any intracellular lipid production; further work will be necessary to establish the nature of the compounds released.

The Nile red fluorescence emission gives information about the time needed by the algae to reach the highest LC. It can be found in the fluorescence emission evolution of the first experimental stage (Fig. 2) that the lipid accumulation begins once the stationary phase is reached (Fig. 1), after around $125 \mathrm{~h}$. On the second stage, experiment $1(-\mathrm{N}-\mathrm{P}-\mathrm{L})$ reaches the fluorescence peak in the first $30 \mathrm{~h}$, implying that only a second stage of 1 day would be needed to achieve the lipid increase observed. Besides, experiment $6(+\mathrm{N}-\mathrm{P}+\mathrm{L})$ requires $300 \mathrm{~h}$ in the second stage to reach the highest fluorescence. On the other hand, experiment $8(+\mathrm{N}+\mathrm{P}+\mathrm{L})$ increasing fluorescence trend suggests that more than $360 \mathrm{~h}$ is needed to obtain the maximum LC.

\section{C/N Ratio}

Biomass $\mathrm{C} / \mathrm{N}$ values of all experiments ranged between 20.87 and 24.97, excepting for experiments $2(+\mathrm{N}-\mathrm{P}-\mathrm{L})$ and $4(+\mathrm{N}+\mathrm{P}-\mathrm{L})$ being 15.17 and 12.54 , respectively. Those experiments presented the higher proportion of nitrogen in the biomass at the end of the second stage, being 3.49 and $4.15 \%$, respectively. Presence of nitrogen and absence of light on the second stage enhanced final biomass nitrogen content.

Determining correctly the composition of microalgae is a way to establish their methane yield and energy potential from the $\mathrm{AD}$. When the $\mathrm{C} / \mathrm{N}$ ratio is below 20 , there is an imbalance between carbon and nitrogen requirements for the anaerobic bacterial community or consortia; nitrogen from protein degradation results in high ammonia concentrations during the $\mathrm{AD}$ treatment inhibiting the methanogenic process [3, 42]. Therefore, all experiments different from $2(+\mathrm{N}-\mathrm{P}-\mathrm{L})$ and $4(+\mathrm{N}+\mathrm{P}-\mathrm{L})$ are susceptible for direct $\mathrm{AD}$.

Ehimen et al. [43] reported the possibility of $\mathrm{AD}$ of low $\mathrm{C} / \mathrm{N}$ microalgae residues from the biodiesel production process by increasing the $\mathrm{C} / \mathrm{N}$ with glycerol, which is a by-product of lipid transesterification. Those authors established that microalgal residues mixed with glycerol at $12.44 \mathrm{C} / \mathrm{N}$ ratio increased $\mathrm{CH}_{4}$ production respecting lesser values of $\mathrm{C} / \mathrm{N}$.

\section{Calorific Value of the Biomass}

Data of HHV obtained via Eq. 4 varied among all experiments (Table 3) ranging all data from 19.58 to $21.92 \mathrm{KJ} / \mathrm{g}$ of experiments $4(+\mathrm{N}+\mathrm{P}-\mathrm{L})$ and $6(+\mathrm{N}-\mathrm{P}+\mathrm{L})$, respectively; these experiments also presented, respectively, the lowest and highest LC. Then, the increase in the calorific values was related to an increase in the LC of the biomass; neutral lipids store significantly more energy than other biomolecules as carbohydrates being 37 versus $17 \mathrm{~kJ} / \mathrm{g}$, respectively [44].

The calorific values obtained are not far from others reported in the bibliography for other microalgae species; Fulke et al. [45] reported calorific values of 29, 34, and $26 \mathrm{~kJ} / \mathrm{g}$ for 
Table 3 Data of calorific values obtained by means of different calculation procedures

\begin{tabular}{llcll}
\hline Experiment & $\begin{array}{l}\text { Calorific value of biomass } \\
\text { based on the calorific value } \\
\text { of lipids }(37 \mathrm{~kJ} / \mathrm{g})(\mathrm{KJ} / \mathrm{g})\end{array}$ & $\begin{array}{l}\text { Increase with } \\
\text { respect to the } \\
\text { first stage }(\%)\end{array}$ & $\begin{array}{l}\text { HHV value of biomass } \\
\text { acording to Callejón-Ferre } \\
\text { et al. [32] (KJ/g d.w.) }\end{array}$ & $\begin{array}{l}\text { Increase with } \\
\text { respect to first } \\
\text { stage }(\%)\end{array}$ \\
\hline 0 (first stage) & 13.52 & 0 & 21.33 & 0 \\
$1(-\mathrm{N}-\mathrm{P}-\mathrm{L})$ & 16.48 & 21.92 & 20.85 & -2.25 \\
$2(+\mathrm{N}-\mathrm{P}-\mathrm{L})$ & 12.74 & -5.80 & 20.5 & -3.89 \\
$3(-\mathrm{N}+\mathrm{P}-\mathrm{L})$ & 13.93 & 3.07 & 20.51 & -3.84 \\
$4(+\mathrm{N}+\mathrm{P}-\mathrm{L})$ & 12.09 & -10.56 & 19.58 & -8.20 \\
$5(-\mathrm{N}-\mathrm{P}+\mathrm{L})$ & 14.49 & 7.17 & 21.17 & -0.75 \\
$6(+\mathrm{N}-\mathrm{P}+\mathrm{L})$ & 17.00 & 25.73 & 21.92 & 2.77 \\
$7(-\mathrm{N}+\mathrm{P}+\mathrm{L})$ & 14.66 & 8.40 & 20.84 & -2.30 \\
$8(+\mathrm{N}+\mathrm{P}+\mathrm{L})$ & 14.95 & 10.59 & 20.48 & -3.98 \\
9 (dark control) & 14.00 & 3.59 & 20.91 & -1.97 \\
$10($ light control) & 15.11 & 11.80 & 20.83 & -2.34 \\
\hline
\end{tabular}

Chlorella sp., Chlamydomonas sp., and Synnecococcus sp., respectively. Scragg et al. [46] reported increased calorific values when cultures where grown in low nitrogen medium, i.e., Chlorella vulgaris from 21 to $28 \mathrm{~kJ} / \mathrm{g}$ and Chlorella emersonii from 21 to $24 \mathrm{~kJ} / \mathrm{g}$.

In this regard, the model proposed by Callejón-Ferre et al. (2011) (Eq. 4) is based on the elemental content of the biomass and does not discriminate between types of biomolecules such as lipids, carbohydrates, and proteins. Thus, HHV from experiments that significantly increased in TL were underestimated. Table 3 shows calorific values of biomass and LC calculated by two different methodologies, the first based on the model proposed by CallejónFerre et al. (2011) (Eq. 4) and the second based on the calorific content of the lipids present in $1 \mathrm{~g}$ of biomass. The calorific value of other biomolecules was obviated, and the calorific value of lipids (37 kJ/g) was taken from Packer et al. [44] (Table 2).

For example, experiment $6(+\mathrm{N}-\mathrm{P}+\mathrm{L})$ presented an increase of $2.77 \%$ in $\mathrm{HHV}$ with respect to the first stage using Eq. 4 [32], and on the other hand, the same calculation for the same case on lipid bases implied a $25.73 \%$ increase of the calorific value (Table 3 ).

Then, calculations based on the elemental content or based on the LC of the biomass differ significantly; the mismatch between both methodologies can imply underestimations in the energy content of microalgae. It is therefore recommended to carry out microalgae energetic estimations based on the LC of the biomass instead of the elemental content.

\section{Conclusion}

In order to increase the lipid content of $A$. falcatus biomass and thus its energetic content, two culturing strategies can be applied once biomass has completed the growth phase. The first one is to maintain the biomass in a photobioreactor under illumination and with the addition of all components of a synthetic culture medium excepting phosphorus. Other cheaper option is to keep the biomass under dark conditions with the addition of all components of a synthetic culture medium excepting nitrogen and phosphorus.

The Nile red method for lipid detection applied in this work presents an abnormal variability related to the production of non-lipidic compounds, being not possible to establish 
a direct relation between the fluorescence and the lipid content of the samples. The absence of nitrogen and the presence of phosphorus in light conditions triggered the synthesis of stainable substances interfering with the Nile red fluorescence signal.

The results from this research show that the two-stage strategy to culture microalgae is a feasible option to produce a biomass with a given composition in order to achieve a biomass with a higher economic or energetic value; future studies with other algae species are needed to evaluate their response in order to know if the proposed strategies are species dependent or not.

\section{References}

1. Razeghifard, R. (2013). Photosynthesis Research, 117, 207-219.

2. Chisti, Y. (2008). Trends in Biotechnology, 26, 126-131.

3. Sialve, B., Bernet, N., \& Bernard, O. (2009). Biotechnology Advances, 27, 409-416.

4. Sheehan, J., Dunahay, T., Benemann, J., \& Roessler, P. (1998). A look back at the U.S. Department of Energy's Aquatic Species Program: biodiesel from algae. Close-out report. Golden: National Renewable Energy Lab, Department of Energy.

5. Griffiths, M. J., \& Harrison, S. T. L. (2009). Journal of Applied Phycology, 21, $493-507$.

6. Hu, Q., Sommerfeld, M., Jarvis, E., Ghirardi, M., Posewitz, M., Seibert, M., \& Darzins, A. (2008). Plant Journal, 54, 621-639.

7. Chen, F., \& Johns, M. R. (1991). Journal of Applied Phycology, 3, 203-209.

8. Illman, A. M., Scragg, A. H., \& Shales, S. W. (2000). Enzyme and Microbial Technology, 27, 631-635.

9. Solovchenko, A. E., Khozin-Goldberg, I., Didi-Cohen, S., Cohen, Z., \& Merzlyak, M. N. (2008). Journal of Applied Phycology, 20, 245-251.

10. Li, Y., Horsman, M., Wang, B., Wu, N., \& Lan, C. Q. (2008). Applied Microbiology and Biotechnology, 81, 629-636.

11. Rodolfi, L., Zittelli, G. C., Bassi, N., Padovani, G., Biondi, N., Bonini, G., \& Tredici, M. R. (2009). Biotechnology and Bioengineering, 102, 100-112.

12. Liang, K., Zhang, Q., Gu, M., \& Cong, W. (2013). Journal of Applied Phycology, 25, 311-318.

13. Harun, R., Danquah, M. K., \& Forde, G. M. (2010). Journal of Chemical Technology and Biotechnology, 85, 199-203.

14. Torri, C., Garcia Alba, L., Samorì, C., Fabbri, D., \& Brilman, D. W. F. (2011). Energy \& Fuels, 26, 658-671.

15. Miao, X., Wu, Q., \& Yang, C. (2004). Journal of Analytical and Applied Pyrolysis, 71, 855-863.

16. Thangalazhy-Gopakumar, S., Adhikari, S., Chattanathan, S. A., \& Gupta, R. B. (2012). Bioresource Technology, 118, 150-157.

17. Courchesne, N. M. D., Parisien, A., Wang, B., \& Lan, C. Q. (2009). Journal of Biotechnology, 141, 31-41.

18. Huntley, M., \& Redalje, D. (2007). Mitigation and Adaptation Strategies for Global Change, 12, 573-608.

19. Prathima Devi, M., Venkata Subhash, G., \& Venkata Mohan, S. (2012). Renewable Energy, 43, 276-283.

20. Kleinegris, D. M. M., Janssen, M., Brandenburg, W. A., \& Wijffels, R. H. (2011). Biotechnology Advances, $29,502-507$.

21. Nascimento, I. A., Marques, S. S. I., Cabanelas, I. T. D., Pereira, S. A., Druzian, J. I., de Souza, C. O., Vich, D. V., de Carvalho, G. C., \& Nascimento, M. A. (2013). Bioenergy Research, 6, 1-13.

22. Kilham, S. S., Kreeger, D. A., Lynn, S. G., Goulden, C. E., \& Herrera, L. (1998). Hydrobiologia, 377, 147-159.

23. APHA. (1998). Standard methods for the examination of water and wastewater (20th ed.). Washington: American Public Health Association.

24. Takagi, M., Karseno, \& Yoshida, T. (2006). Journal of Bioscience and Bioengineering, 101, 223-226.

25. Wiltshire, K. H., Boersma, M., Möller, A., \& Buhtz, H. (2000). Aquatic Ecology, 34, 119-126.

26. Chen, W., Zhang, C., Song, L., Sommerfeld, M., \& Hu, Q. (2009). Journal of Microbiological Methods, 77, $41-47$.

27. De La Jara, A., Mendoza, H., Martel, A., Molina, C., Nordströn, L., De La Rosa, V., \& Díaz, R. (2003). Journal of Applied Phycology, 15, 433-438.

28. Chen, W., Sommerfeld, M., \& Hu, Q. (2011). Bioresource Technology, 102, 135-141.

29. Verhulst, P. F. (1838). Correspondance mathématique et physique. 10, 113-121.

30. Lasdon, L. S., Waren, A. D., Jain, A., \& Ratner, M. (1978). Design and testing of a generalized reduced gradient code for nonlinear programming. ACM Transactions on Mathematical Software, 4, 34-50.

31. Everit, B. S., \& Skrondal, A. (2010). The Cambridge dictionary of statistics (4th ed.). Cambridge: Cambridge University. 
32. Callejón-Ferre, A. J., Velázquez-Martí, B., López-Martínez, J. A., \& Manzano-Agugliaro, F. (2011). Renewable and Sustainable Energy Reviews, 15, 948-955.

33. Kilham, S. S., Kreeger, D. A., Goulden, C. E., \& Lynn, S. G. (1997). Freshwater Biology, 38, 591-596.

34. Wolff, L., Flemming, J., Schmitz, R., Gröger, K., Goso, C., \& Müller-Goymann, C. C. (2009). Colloids and Surfaces A: Physicochemical and Engineering Aspects, 339, 82-93.

35. Bhatia, S., Mohr, A., Mathur, D., Parmar, V. S., Haag, R., \& Prasad, A. K. (2011). Biomacromolecules, 12, 3487-3498.

36. Passow, U. (2002). Progress in Oceanography, 55, 287-333.

37. Myklestad, S. (1977). Journal of Experimental Marine Biology and Ecology, 29, 161-179.

38. Ding, Y. X., Hung, C. C., Santschi, P. H., Verdugo, P., \& Chin, W. C. (2009). Terrestrial, Atmospheric and Oceanic Sciences, 20, 741-747.

39. Chen, C. S., Anaya, J. M., Zhang, S., Spurgin, J., Chuang, C. Y., Xu, C., Miao, A. J., Chen, E. Y. T., Schwehr, K. A., Jiang, Y., Quigg, A., Santschi, P. H., \& Chin, W. C. (2011). PLoS ONE, 6(7), e21865.

40. Vieira, A. A. H., \& Myklestad, S. (1986). Journal of Plankton Research, 8, 985-994.

41. Paulsen, B. S., Aslaksen, T., Freire-Nordi, C. S., \& Vieira, A. A. H. (1998). Journal of Phycology, 34, 638-641.

42. Heaven, S., Milledge, J., \& Zhang, Y. (2011). Biotechnology Advances, 29, 164-167.

43. Ehimen, E. A., Sun, Z. F., Carrington, C. G., Birch, E. J., \& Eaton-Rye, J. J. (2011). Applied Energy, 88, 3454-3463.

44. Packer, A., Li, Y., Andersen, T., Hu, Q., Kuang, Y., \& Sommerfeld, M. (2011). Bioresource Technology, 102, 111-117.

45. Fulke, A. B., Mudliar, S. N., Yadav, R., Shekh, A., Srinivasan, N., Ramanan, R., Krishnamurthi, K., Devi, S., \& Chakrabarti, T. (2010). Bioresource Technology, 101, 8473-8476.

46. Scragg, A. H., Illman, A. M., Carden, A., \& Shales, S. W. (2002). Biomass and Bioenergy, 23, 67-73. 